\title{
Scientific Application of Standard Costing Practices in Manufacturing Industries - A Case Study
}

\section{OPEN ACCESS}

Manuscript ID:

COM-2021-09044356

Volume: 9

Issue: 4

Month: October

Year: 2021

E-ISSN: 2582-6190

Received: 18.07.2021

Accepted: 25.08.2021

Published: 01.10.2021

Citation:

Sil, Kunal. "Scientific Application of Standard Costing Practices in Manufacturing Industries - A Case Study." ComFin Research, vol. 9, no. 4, 2021, pp. 27-33.

DOI:

https://doi.org/10.34293/ commerce.v9i4.4356

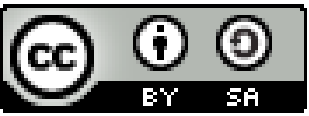

This work is licensed under a Creative Commons Attribution-ShareAlike 4.0 International License
Kunal Sil

Post Doctorate Research Fellow, Srinivas University, Karnataka, India

https://orcid.org/0000-0002-6992-5285

\section{Abstract}

Standard Costing is one of the very traditional and yet important tools in cost accounting. It plays a crucial role in controlling the costs of an organisation. The purpose of this study is to explore how standard costing could be effectively used in even small scale industries. With the emergence of modern scientific accounting systems, few experts have placed their opinion against standard costing, marking it as obsolete and dysfunctional. But, the outcome of this study has shown that the application of standard costing as modern management tools is still very much acceptable and in vogue. The lack of proper knowledge of standard costing is the only perceived hindrances in using and applying the same. Like any evolving field, this has to be applied scientifically to fetch the maximum benefit.

Keywords: Standard costing, Cost control, Scientific accounting and modern management tools

\section{Introduction}

Today, information is provided in both financial and non-financial firms. This information mainly pertains to cost data regarding obtaining and applying recourses of an organisation. This is how; it has become an essential part of the long-term survival of an organisation. Cost data is used for various purposes, right from strategy formulation to pricing methods. The advent of the industrial revolution has brought significant changes in the methods of cost accounting. As suggested by Waweru (1), the industrial revolution has distinguished ownership from infrastructure, and the entity concept of accounting emerged. Workers began to recruit for the long term and rapid growth of transportation has given birth to new concepts, such as cost/ton, cost/mile etc.

The United States of America has traced greater importance of cost accounting and control practices to aid large scale production and distribution systems between 1850-1875(1). It has also been subsequently noted that the necessity for internal planning and control had to be channelised in such a way that coordination between multiple stages become easier and smooth. Cost Accounting practices in the last century did not incorporate scientific concepts like cost allocation, neither to products or periods. The champion of Scientific Management emphasised job analysis, rotation of duties and motion studies that require logical standards for several labour and quantity of material needed for a certain level of output. These were accepted as a standard for paying them on a piecemeal basis (2).

The prevalent cost accounting techniques employed till 1950 have not included the concept of Just in Time. Some popular cost accounting systems like Absorption Costing, Standard Costing and Marginal Costing techniques were highly defamed due to loss of relevance(3). 
Pioneering work was done by Professor Clark at the end of the 20th Century regarding the treatment of overhead costs and their implied significance on managerial decision making. Many popular concepts of today like sunk cost, differential cost or incremental cost could be traced in Clark's treatise (2).

The innovations in cost accounting concepts are widely used in increasing the efficiency of the unit in multiplying mass production with a certain level of product standardisation. Cost data was primarily used to measure operating efficiency, setting prices along with motivating workers for better performance. Most cost techniques developed during the last part of the 19th Century and the beginning of the 20th century had no innovativeness. These are now regarded as traditional techniques, like Standard Costing, Marginal Costing and Absorption Costing. The criticisms spearheaded by Kaplan and Johnson (2) pointed out that management accounting has no role in the dynamism of the organisation.

The fallouts of traditional methods have given birth to new accounting techniques, such as $\mathrm{ABC}$, Target Costing, Life Cycle Costing and JIT as a measure to control "relevance loss".

\section{Objectives}

The objective of this paper is to evaluate the effectiveness of cost accounting techniques that were used in the service and manufacturing industries in the last century.

\section{Theory of Contingency}

It is an approach of rganisational behaviour that tells how contingent factors like external environment, technology and culture influences the layout and functionality of the organisation. Another significant explanation of this theory depends on dependent variables. It is a relationship between two phenomenons- if one exists then only decisions can be drawn on another. Contingency theories have been applied in accounting for many years and in several means. Professor Hofstede (6) has observed that technological, economic and societal factors have a tremendous bearing on budgeting systems. Dr.Shank (7) has also used contingency principles on managerial accounting in a strategic manner. Datar
(8) had considered the effect of structural factors in implementing JIT or team-based performances to measure the performance of shop floor workers. There has always been a difference in U.S and Japan while applying cost accounting practices. The U.S has emphasised on career objectives of cost accountants, while Japan uses the same for motivating employees. In Japan, direct labour overheads alter the product cost; still, it is being used to incentivise labour efficiency. Most of the students of accounting are trained in different institutions in their career in Accounting. Still, Japan rotates their students to different functional areas, like accounting or production, after a certain period. They gather huge experience in the same field and then are sent to the accounting department.

\section{Costing Techniques}

Traditional cost tools such as Standards Costing, Marginal Costing and Absorption Costing have been heavily criticised for being irrelevant in today's context and changing business periphery. A whole lot of modern costing techniques have emerged from various scholars. These include Activity Based Techniques (ABC), Target Costing, Life Cycle Costing and Just in Time Concepts. These are considered as more scientific approaches to costing.

\section{Standard Costing}

As per CIMA, Standard costing is a technique of reporting variances by making a comparison between actual and pre-determined costs. It facilitates action through management by exception. It uses standards as techniques for both cost and revenue with an objective of control by applying variance analysis. Standards are set on each cost element upon a rational basis. Every variance from such standard is analysed and corrective actions are taken consecutively. As mentioned by Professor Kuchksavas (15), the objective of standard cost is to give relevant and useful information for cost controlling and fastens areas like budget preparation, product pricing and divisional performance measurement. Standard Costing is primarily used in manufacturing organisations like Petroleum, Pharmaceuticals, Chemical, Automotive and Canned food industries. Though standard costing is widely practised in 
manufacturing organisations, its importance in nonmanufacturing need not be overemphasised.

Kaplan (4) have criticised standard costing on the ground of its inappropriateness in today's highly dynamic and competitive world. Drury (2009) has also observed that the application of standard costing is questionable in the modern world, especially in 21 st Century as cost components have changed and modern management approaches are inconsistent.

\section{Absorption Costing}

This method of costing is also known as Full Costing. It considers all the costs as a part of product cost and pays no attention, whether fixed or variable. This is primarily used while making financial statements of an organisation. It ensures that all costs have been retrieved and shows the correct profit calculation. It endorses both matching and accrual principles of accounting. ICAN (18) has opined that absorption costing has limited value in an automated production environment where production overhead is significantly important than direct labour cost.

\section{Marginal Costing}

Another name of Marginal Costing is Variable Costing, as it intentionally separates variable and fixed costs for efficient managerial decision making. It draws management attention to changes resulting from decision variables. It is a proven tool for short-term and quick decision making such as Accept-Reject, Make-Buy or Special order. It has even proved to be very useful in answering critical questions like whether a particular line of business would be dropped or the same would be tendered to outsiders.

\section{Just in Time (JIT)}

Just in Time is a brainchild of Toyota Motor Company, which emerged to reduce flow times within production and supply. Developed in Japan in the early 1970s, this model was migrated to the Western part of the globe for an effective and swift manufacturing process. This system reduces inventory/stock and has been in use for many years. Omar (29) has observed that manufacturers must deliver products in small units to minimise buyer's cost of holding. JIT is believed to be based on a pull system of production that abolishes the concept of total inventory. Just in Time has been witnessed phenomenal success in developed countries with modern production systems and large business houses.

Siha, Luminous and Duclos (32) have also seen that JIT is not only appropriate for manufacturing industries but equally applicable for service concerns like Insurance, Banks, Hotel and Tourism and Audit firms. It is so because JIT is process-driven rather than product-driven.

\section{Activity-Based Costing (ABC)}

This technique was pioneered by Professor Cooper in the mid of 1980s. It was introduced primarily to correct delude allocation of overhead. It is envisaged as a distilling cost system that allows more cost as a direct cost and enlarges the indirect cost pool. This method advocates effective cost allocation using small cost centres as units. Cost drivers are used as a basis for allocating costs to other cost-object like products/services.

As mentioned by CIMA $(11,12), \mathrm{ABC}$ is an approach of costing final outputs by supervising the activities and tracking the consumption pattern of recourses. Resources are categorised as per activity and activities to cost-object. A very recent development in the field of Activity Based Costing is Activity-Based Management (ABM). Kaplan and Burns (18) mentioned very clearly that $\mathrm{ABC} / \mathrm{ABM}$ does not consider those activities that add no or little value to the Customer. Many times, the application of $\mathrm{ABC}$ is both costly and time-consuming (Media and Rojas).

\section{Target Costing}

Target costing came into practice due to crucial challenges posed by the consumers for greater diversity and a short product life cycle. Companies have also witnessed that cost to the product is assigned at the designing stage. It has emerged as a multi-disciplinary approach of managing costs from the early stages. These stages were accompanied by modern techniques like process re-engineering and TQM. It sets a target cost by taking away a preferred profit margin in a perfectly competitive market.

Though the motive behind introducing target 
costing was to serve manufacturing industries, it is effective for service industries too. The key issues about target costing are to understand the market needs and benefits comprise classification of products and services in the early stage of development.

\section{Throughput Costing}

CIMA (11) has defined Throughput Costing as a technique of Accounting used with the objective of maximising output while parallel inventory or decrease in inventory costs. This technique of management has a direct impact on managerial decision making. It focuses on the goal of the organisation and to achieve the purpose through different goal-units. This is the rate at which an entity measures and achieves its goal. In nonfinancial entities, the goal could be measured in nonfinancial terms, but in a profit-seeking industry, the goal is profit. Throughput Accounting is a recent development in a modern management system that permits the management to make proper use of constrained resources; as per ICAN (18), Throughput costing aids in performance management for taking a comprehensive analytical decisions.

\section{Life Cycle Costing}

It is also known as "Whole Life Cycle Costing" and endeavours to identify the total cost associated with using an asset. Life Cycle Costing is a widely used tool by companies and governments to evaluate the cost of an asset through its life period. The primary advantages of life cycle costing include improved managerial responsiveness and evaluation of options. LFC is mostly applicable where initial capital investment is high. An Insurance Organization or a Credit Card Company spend a huge amount on account of paper documentation, credit viability and policies for the new customers before the initial investment is recovered(2).

\section{Kaizen Costing}

It means continuous improvement affecting everybody from the front line to the top level of management. Kaizen is derived from the Japanese philosophy of "improving upon the existing situation". This method could be effectively used for productivity improvement and to gain a competitive advantage. Kaizen is a very recognised method of performance management while keeping the cost of operation at a minimum level.

\section{Back Flush Costing}

Back Flush is also recognised as delayed product costing. It has become one of the simplest techniques of cost accumulation for those companies that have already adopted the JIT system. However, it must be remembered that JIT is not a mere technique but encompasses a broad philosophy of continuous up-gradation and loss reduction due to operations. This new system of costing has responded to the basic requirements of JIT mechanism. It is a strong theoretical assumption of assigning cost and mitigating inventory.

\section{Empirical Evidence \\ Cost Accounting in Manufacturing Industries}

Sulaiman et al. (39) conducted a research study on Strategic Management Accounting and found that instruments of strategic cost management were strategic pricing, customer accounting and benchmarking. These techniques were mostly used by European manufacturing companies and mostly related to implementation cost and non-financial information. It plays a very important role in determining product price.

Saayadah and Khatatneh (40) carried out a research study to find out the effects of recent tools of cost management on Nigerian companies. The authors have taken 40 companies which comprises a $30 \%$ of the targeted population. It confirmed an acceptable level of awareness and adaptation of JIT, Balanced Score Card and Target Costing.

Dury, Badem and Egrin(17) have investigated one Turkish Automobile Industry with three survey methods- electronic questionnaire, telephone and one-to-one interview. The outcome showed an average use of $80 \%$ of standard costing.

Karanja and Nyaanga (42) have studied SMEs of developing countries. The research study showed that both modern and traditional methods of costing are adopted to enhance organisational efficiency and better product or service pricing. The same research study has highlighted that most SMEs have capital inadequacy problems. 
Dr Mazumdar (43) has done another research study on the application of the efficacy of Management Accounting on some business firms of Bangladesh and found that management accounting techniques are almost used at a satisfactory level. Only a few large business houses use modern management accounting techniques, such as JIT, TQM etc.

\section{Cost Accounting Techniques Adopted by Service Companies}

Ashfaq, Hanif, Younas and Usman [48) examined the role of both conventional and recent management accounting practices regarding their role and utility on the Business Cycle of Financial Sectors of Islamic Countries. The data were collected using a structured questionnaire and from 95 service companies like Insurance, Bank, Telecommunications and Computer Services. Statistical results show clearly $70 \%$ of companies were in the growth phase and $25 \%$ of companies were in maturity and saturated stages. However, when it comes to evaluating performance, non-financial measures were found to have low applications.

A research study of Management Accounting Practices among manufacturing and service industries in Bangladesh was done by Md.Yeshmin and Fowzia (49) to examine the effectiveness of managerial accounting in carrying out all managerial functions. The author investigated 150 plus organisations and used a structured questionnaire with 5point Likert Scale. They used 13 management accounting techniques, such as Cash Flow, Budget, Financial Statements, TQM, Variance Analysis, Fund Flow and Activity Based Costing.

Vander Poll(50) carried out a study on the competitive advantage of the banking industry with 42 sample banks. The study brought a new dimension in Management Accounting practices and it has been found that it plays a key role in planning, organising, developing and evaluating of strategic policies for an organisation.

\section{Discussion \& Conclusion}

The objective is to find out the effectiveness of cost accounting techniques used in manufacturing and service industries. Few traditional techniques like
Marginal and Absorption techniques were severely criticised on the ground of less compatibility. The modern business environment is characterised by innovation, hard competition, customer satisfaction and the global market. The empirical study, however, showed the importance of Standard Costing and Absorption Costing in certain cases.

Activity-Based Costing (ABC) has become the most acclaimed accounting practice in service industries. Cost Volume Profit Analysis, Budgetary Control, Variance Analysis has become a very common tool to the service industries.

\section{Recommendations}

1. Companies need to select costing techniques considering their business environments like technology, advertisement, the volume of demand and product stage.

2. Research and Development (R\&D) must be made a part of business activities.

3. Time tested techniques will be preferred more than new methods could be tried upon.

\section{References}

Askarany, Davood. Technological Innovations, Activity based Costing and Satisfaction. 2006.

Ahmad, Azmi, et al. "The Declining Need for Traditional Performance Measures in JIT Practices." Journal of Business Administration Online, vol. 1, no. 2, 2002.

Ashfaq, Khurram, et al. “Traditional vs Contemporary Management Accounting Practices and its Role and Usage across Business Life Cycle Stages: Evidence from Pakistani Financial Sector." International Journal of Academic Research in Accounting, Finance and Management Science, vol. 4, no. 4, 2014, pp. 104-125.

Activity Based Costing Gateway series No 1. CIMA, 2008.

Banker, Rajiv D., et al. "A Model to Evaluate Variables Impacting the Productivity of Software Maintenance." Journal of Management Science, vol. 37, no. 1, 1991.

Badem, A. Cemkut, et al. "Is Standard Costing Still Used? Evidence from Turkish Automotive Industry." International Business Research, 
vol. 6, no. 7, 2013, pp. 79-90.

Boca, Gratiela Dana. "Kaizen Method in Production Management." International Scientific Conference Young Scientists, 2011.

Barkman, William. In-Process Quality Control for Manufacturing. CRC Press, 1989.

Canel, Cem, et al. "Just in Time is not Just for Manufacturing: A Service Perspective." Industrial Management and Data System, vol. 100, no. 2, 2000, pp. 51-60.

Charaf, Karim, and Ahmed Rahmouni. "Using Importance Performance Analysis to Evaluate the Satisfaction of Activity-Based Costing adopters." Accounting and Management Information Systems, vol. 13, no. 4, 2014, pp. 665-685.

Duclos, Leslie K., et al. "JIT in Services: A Review of Current Practices and Future Directions for Research." International Journal of Service Industry Management, vol. 6, no. 5, 1995, pp. 36-52.

Dugdale, David, et al. "Contemporary Management Accounting Practices in UK Manufacturing." CIMA, vol. 1, no. 13, 2005.

Domingo, Tony Mendes. The Application of Activity Based Cost and Management to support Competitive Strategy in the Banking Sector: A South African Case Study. University of Cape town, 2007.

Ekibatani, M.A., and M.A. Sangeladji. "Traditional vs. Contemporary Managerial / Cost Accounting Techniques: Differences between Opinions of Educators and Practitioners." International Business \& Economics Research Journal, vol. 7, no. 1, 2008, pp. 93-112.

Effective Performance Management with the Balanced Scorecard. CIMA, 2005.

Goddard, Walter E. Just-in-Time: Surviving by Breaking Tradition. Oliver Wight Ltd, 1986.

Hofstede, Geert. "The Cultural Relativity of Organizational Practices and Theories." Journal of International Business Studies, vol. 14, 1983, pp. 75-89.

Hall, Robert W. Zero Inventories. Dow Jones-Irwin, 1983

High, Will. "Short Cycle Management (SCM) Implementation: An Approach Taken at
Motorola." Target, 1987, pp. 19-24.

Hyer, Nancy, and Urban Wemmerlov. Reorganizing the Factory: Competing through Cellular Manufacturing. Productivity Press, 2002.

Islam, Jesmin, and Hui Hu. "A Review of Literature on Contingency Theory in Managerial Accounting." African Journal of Business Management, vol. 6, 2012.

Kaplan, Robert S. "The Evolution of Management Accounting." The Accounting Review, vol. 59, no. 3, 1984, pp. 390-418.

Kaplan, Robert S., and H. Thomas Johnson. Relevance Lost: The Rise and Fall of Management Accounting. Harvard University Press, 1987.

Karanja, Joseph Crispus, et al. Adoption of Modern Management Accounting Techniques in Small and Medium (SMES) in Developing Countries: A Case Study of SMEs in Kenya.

Kootanaee, Akbar Javadian, et al. "Just-in-Time Manufacturing System: From Introduction to Implement." International Journal of Economics, Business and Finance, vol. 1, no. 2, 2013, pp. 7-25.

Marie, Attiea, et al. "Is Standard Costing still Relevant? Evidence from Dubai." Management Accounting Quarterly, vol. 11, no. 2,2010

Mazanai, Musara. "Impact of Just-in-time (JIT) Inventory System on Efficiency, Quality and Flexibility among Manufacturing Sector, Small and Medium Enterprise (SMEs) in South Africa." African Journal of Business Management, vol. 6, 2012.

Ohno, Taiichi. Toyota Production System: Beyond Large-Scale Production. Diamond Publishing, 1978.

Omar, Mohd, and Hafizah Zulkipli. "An Integrated Just-in-Time Inventory System with StockDependent Demand." Bulletin of the Malaysian Mathematical Sciences Society, vol. 37, 2013.

Ramezani, Amir Reza, and Mohammad Mahdloo. "Backflush Costing and Backflush Accounting." Academic Journal of Research in Business \& Accounting, vol. 2, no. 5, 2014. Roebuck, Kevin. Business Process Modeling: 
High-impact Emerging Technology - What You Need to Know: Definitions, Adoptions, Impact, Benefits, Maturity, Vendors. Tebbo, 2011.

Shank, John K. "Strategic Cost Management: New Wine or Just New Bottles." Journal of Management Accounting Research, 1989, pp. 47-65.

Shields, Michael D., et al. "Management Accounting Practices in the U.S. and Japan: Comparative Survey Findings and Research Implications." Journal of International Financial Management and Accounting, vol. 3, no. 1, 1991.

Singh, D.K., and Satyendra Singh. "JIT: A Strategic Tool of Inventory Management." International Journal of Engineering Research and Applications, vol. 3, no. 2, 2013, pp. 133-136.

Sulaiman, Maliah, et al. "Is Standard Costing Obsolete? Empirical Evidence from Malaysia." Managerial Auditing Journal, vol. 20, no. 2, 2005, pp. 109-124.

Theory of constraint and Throughput Accounting. CIMA, 2007.

Waweru, Nelson Maina. "The Origin and Evolution of Management Accounting: A Review of the Theoretical Framework." Problems and Perspectives in Management, vol. 8, no. 3,
2010, pp. 165-182.

Wegmann, Gregory. “Activity-based Management in France: A Focus on the Information Systems Department of a Bank." International Conference on Economics, Business and Marketing Management, 2011.

Williamson, Duncan. Cost and Management Accounting. Prentice Hall, 1996.

Wijewardena, Hema, and Anura De Zoysa. "A Comparative Analysis of Management Accounting Practices in Australia and Japan: An Empirical Investigation." International Journal of Accounting, vol. 34, no. 1, 1999, pp. 49-70.

Womack, James P., et al. The Machine That Changed the World: The Story of Lean Production. Harper Business, 1991.

Valadez, Ray M., et al. “Applying Marginal Analysis in Determining the Number of Contractors: An Approach for the Advisory and Assistance Services (A \& AS) and Department of Defense (DOD)." Research in Higher Education Journal, 2014.

Yeshmin, Farjana, and Rehana Fowzia. "Management Accounting Practices: A Comparative Analysis of Manufacturing and Service Industries." ASA University Review, vol. 4, no. 1, 2010, pp. 131-141.

\section{Author Details}

Dr. Kunal Sil, Post Doctorate Research Fellow, Srinivas University, Karnataka, India,

Email ID: kunalsil1980@gmail.com. 